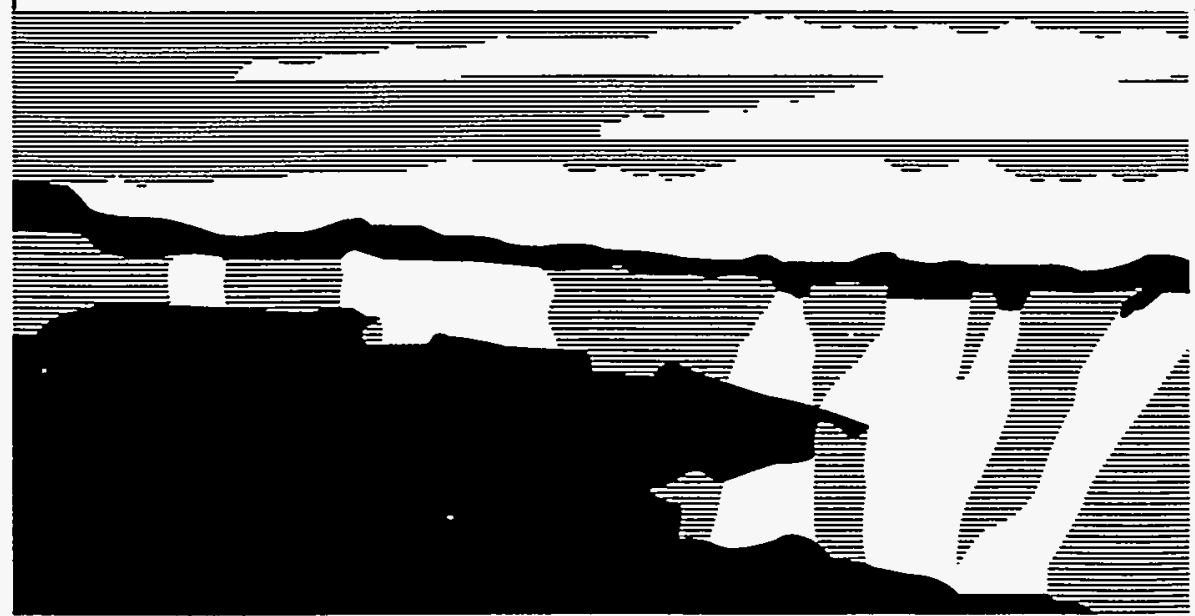

Los Alamos National Laboratory, an affirmative actionequal opportunity employer, is operated by the University of Califomia for the U.S. Department of Energy under contract W-7405-ENG-36. By acceptance of this article, the publisher recognizes that the U.S. Govemment retains a nonexclusive, royalty-free license to publish or reproduce the published form of this contribution, or to allow others to do so, for U.S. Government purposes. Los Alamos National Laboratory requests that the publisher identify this article as work performed under the auspices of the U.S. Department of Energy. The Los Alamos National Laboratory strongly supports academic freedom and a researcher's right to publish; as an institution, however, the Laboratory does not endorse the viewpoint of a publication or guarantee its technical correctness. 


\section{DISCLAIMIER}

Portions of this document may be illegible in electronic image products. Images are produced from the best available original document. 


\section{DISCLAIMER}

This report was prepared as an account of work sponsored by an agency of the United States Government. Neither the United States Government nor any agency thereof, nor any of their employees, make any warranty, express or implied, or assumes any legal liability or responsibility for the accuracy, completeness, or usefulness of any information, apparatus, product, or process disclosed, or represents that its use would not infringe privately owned rights. Reference herein to any specific commercial product, process, or service by trade name, trademark, manufacturer, or otherwise does not necessarily constitute or imply its endorsement, recommendation, or favoring by the United States Government or any agency thereof. The views and opinions of authors expressed herein do not necessarily state or reflect those of the United States Government or any agency thereof. 


\title{
End Point Control of an Actinide Precipitation Reactor
}

\author{
Kenneth R. Muske \\ Department of Chemical Engineering, Villanova University, Villanova, PA 1908 $E$ EEIVED \\ and \\ Michael J. Palmer \\ Los Alamos National Laboratory, Los Alamos, NM 87545 \\ AUG 131997
OSTI
}

\begin{abstract}
An end point control algorithm for the semi-batch actinide precipitation reactors at Los Alamos National Laboratory is described. The algorithm is based on an equilibrium solubility model of the chemical species in solution. This model is used to predict the amount of base hydroxide necessary to reach the end point of the actinide precipitation reaction. The model parameters are updated by on-line $\mathrm{pH}$ measurements.
\end{abstract}

\section{Process Description}

The actinide precipitation reactors in the nuclear materials processing facility at Los Alamos National Laboratory are used to remove actinides and other heavy metals from the effluent streams generated during the purification of plutonium. These effluent streams consist of hydrochloric acid solutions, ranging from one to five molar in concentration, in which actinides and other metals are dissolved. The actinides present are plutonium and americium. Typical actinide loadings range from one to five grams per liter. The most prevalent heavy metals are iron, chromium, and nickel that are due to stainless steel. Removal of these metals from solution is accomplished by hydroxide precipitation during the neutralization of the effluent. In addition, sodium, potassium, magnesium, and calcium may be present from the electrochemical purification processes used to refine plutonium.

In order to prevent the possibility of a nuclear chain reaction, the amount of fissionable material present is limited by carrying out the reaction in batches using several low volume, semi-batch reactors. Each reactor is initially charged with effluent to which base hydroxide is added until the neutralization reaction is complete. Recovery of the precipitated heavy metal hydroxides is accomplished by filtration of the reactor contents. The reactors are located within a glovebox to protect operating personnel from radiation.

Although the actinide hydroxides are essentially completely insoluble in the neutralized solution, aqueous base addition generally results in a drown-out precipitation in which a significant fraction of the solids are sub-micron particles that are difficult to remove from solution. Because of the radioactivity and chemical toxicity of the actinides, complete recovery of these elements is necessary before transferring the neutralized effluent streams to the waste treatment facility. For this reason, magnesium hydroxide powder is used in this process [1]. Precipitation occurs as the powder is dissolved by the acid yielding a larger mean precipitate particle size and a significant reduction in the amount of sub-micron particles as compared to the use of aqueous hydroxide. The result is reduced settling time of the precipitate with faster and more efficient filtering of the neutralized solution. In addition, any sodium, potassium, and calcium present will not coprecipitate with the heavy metals since magnesium hydroxide has a lower solubility limit.

The disadvantage of the use of magnesium hydroxide powder is the difficulty in accurately transferring a given amount into the glovebox and adding it to the reactor. This makes precise control to the end point difficult to achieve. If the end point is not achieved, unprecipitated actinides will be left in solution and the batch will have to be reprocessed. Since reprocessing can significantly reduce capacity, typical operating practice is to add excess magnesium hydroxide to the reactor to ensure complete actinide precipitation. However, this practice produces unreacted magnesium hydroxide in the precipitate.

Unreacted magnesium hydroxide results is an increase in the high level solid radioactive waste produced by this process. The magnesium nuclei in the precipitate also generate neutron radiation from interaction with alpha particles. The isotopes of plutonium all experience alpha decay in which a uranium isotope and alpha particle are produced.

$$
{ }_{94}^{n} \mathrm{Pu} \longrightarrow{ }_{92}^{n-4} \mathrm{U}+{ }_{2}^{4} \alpha
$$

The isotope plutonium-241 can also experience beta decay forming americium-241. Americium-241 rapidly undergoes alpha decay and is the most significant source of alpha radiation in this process.

$$
\begin{aligned}
{ }_{94}^{241} \mathrm{Pu} & \rightarrow{ }_{95}^{241} \mathrm{Am}+{ }_{-1}^{0} \beta \\
{ }_{95}^{44} \mathrm{Am} & \rightarrow{ }_{93}^{237} \mathrm{~Np}+{ }_{2}^{4} \alpha
\end{aligned}
$$


The alpha radiation produced by these nuclear reactions is easily shielded and not a concern. However, alpha particles interact with the nuclei of light elements, such as the isotopes of magnesium, by $(\alpha, n)$ reactions to form neutrons.

$$
\begin{aligned}
& { }_{12}^{26} \mathrm{Mg}+{ }_{2}^{4} \alpha \rightarrow{ }_{14}^{29} \mathrm{Si}+{ }_{0}^{1} \mathrm{n} \\
& { }_{12}^{25} \mathrm{Mg}+{ }_{2}^{4} \alpha \rightarrow{ }_{14}^{28} \mathrm{Si}+{ }_{0}^{1} \mathrm{n} \\
& { }_{12}^{24} \mathrm{Mg}+{ }_{2}^{4} \alpha \rightarrow{ }_{13}^{27} \mathrm{Al}+{ }_{1}^{0} \beta+{ }_{0}^{1} \mathrm{n}
\end{aligned}
$$

The neutron radiation formed by these interactions is a processing concern that needs to be minimized while ensuring complete actinide recovery from the effluent.

\section{End Point Control Objectives}

Consistently achieving the end point with each batch minimizes the high level solid radioactive waste and $(\alpha, n)$ neutron radiation produced by the process and ensures complete actinide precipitation. However, operation with manual addition of magnesium hydroxide and a chemical indicator to infer $\mathrm{pH}$ makes this consistency almost impossible to achieve. For this reason, it was decided to automate the precipitation reactor and implement computer control of the end point. An additional benefit of automation is a significant reduction in the radiation exposure to the operating personnel for this process.

The objective of end point control in this process is to add magnesium hydroxide until the solubility limit is achieved. Due to the solubility difference between magnesium hydroxide and the actinide hydroxides, essentially all of the actinides will be precipitated at this point while essentially all of the magnesium will remain in solution. The solubility difference between magnesium hydroxide and the hydroxides of sodium, calcium, and potassium ensures that essentially all of these metals will also remain in solution.

Determination of the solubility limit is difficult to achieve with $\mathrm{pH}$ measurements due to the nonlinear increase in $\mathrm{pH}$ at the end point. This response coupled with the inability to precisely add very small amounts of magnesium hydroxide suggests that conventional feedback control based on $\mathrm{pH}$ measurements is not adequate. Therefore, a model-based approach is adopted.

\section{Process Instrumentation}

An AccuRate Model 304 loss-in-weight dry material feeder was selected to automatically feed the magnesium hydroxide powder. Magnesium hydroxide tests conducted by AccuRate on this model showed an average $0.4 \%$ relative error which is sufficient for this application. The feeder is located on top of the glovebox containing the reactors. The magnesium hydroxide powder enters the feed line by gravity flow where it is then sparged into the bottom of the reactor along with fluidization air. The pressure differential is supplied by operating the reactors under vacuum. Isolation between the feed line and reactor is by automatic air-operated ball valves located inside the glovebox.

On-line $\mathrm{pH}$ measurements are supplied by a $\mathrm{pH}$ probe installed at the base of the reactor. In addition to the $\mathrm{pH}$ measurements, each batch is titrated before processing. Titration of the charged effluent is carried out by an automated standard potassium hydroxide titration unit located inside the glovebox.

The volume of the effluent charged to the reactor is measured using a differential pressure sensor. Since the reactors are uniform cylindrical glass vessels, no geometric corrections to the pressure sensor reading are required.

\section{Process Model}

An equilibrium solubility model is used to describe the precipitation reaction for end point control. The model is based on the algebraic charge balance and equilibrium solubility of the ions in solution. The charge balance is expressed as follows in which $\mathrm{M}^{+3}$ represents the actinide and heavy metal ions, $\mathrm{A}^{+}$represents the alkali metal ions, and brackets indicate molar concentration of the species.

$$
3\left[\mathrm{M}^{+3}\right]+2\left[\mathrm{Mg}^{+2}\right]+\left[\mathrm{A}^{+}\right]+\left[\mathrm{H}^{+}\right]=\left[\mathrm{OH}^{-}\right]+\left[\mathrm{Cl}^{-}\right]
$$

The equilibrium constant for the autoprotolysis of water and the equilibrium solubility products of the magnesium and heavy metal hydroxides are presented below.

$$
\begin{aligned}
& \mathrm{K}_{\mathrm{w}}=\left[\mathrm{H}^{+}\right]\left[\mathrm{OH}^{-}\right] \quad=1.0 \times 10^{-14} \\
& \mathrm{~K}_{\mathrm{Mg}}=\left[\mathrm{Mg}^{+2}\right]\left[\mathrm{OH}^{-}\right]^{2}=1.3 \times 10^{-11} \\
& \mathrm{~K}_{\mathrm{M}}=\left[\mathrm{M}^{+3}\right]\left[\mathrm{OH}^{-}\right]^{3}=1.6 \times 10^{-30}
\end{aligned}
$$

The solubility product of the combined actinide and heavy metal hydroxides is taken as that for chromium hydroxide which is the most soluble. The solubility products are valid only when solid hydroxide is present in the system. When no solid is present, the product of the equilibrium concentrations will be less than the solubility product. The solubility limit is the point when the product of the equilibrium concentrations equals the solubility product without a precipitate.

Figure 1 presents a simulated titration curve for one liter of effluent containing $5 \mathrm{~g} / \mathrm{l}$ heavy metals in $2 \mathrm{M}$ hydrochloric acid. The end point occurs at a $\mathrm{pH}$ of 8.7. Additional magnesium hydroxide precipitates and does not raise the $\mathrm{pH}$ after this point. The slight change in slope around a $\mathrm{pH}$ of 5 is due to the precipitation of the heavy metals. The sharp corner at the end point is a result of assuming no change in volume from the addition. 


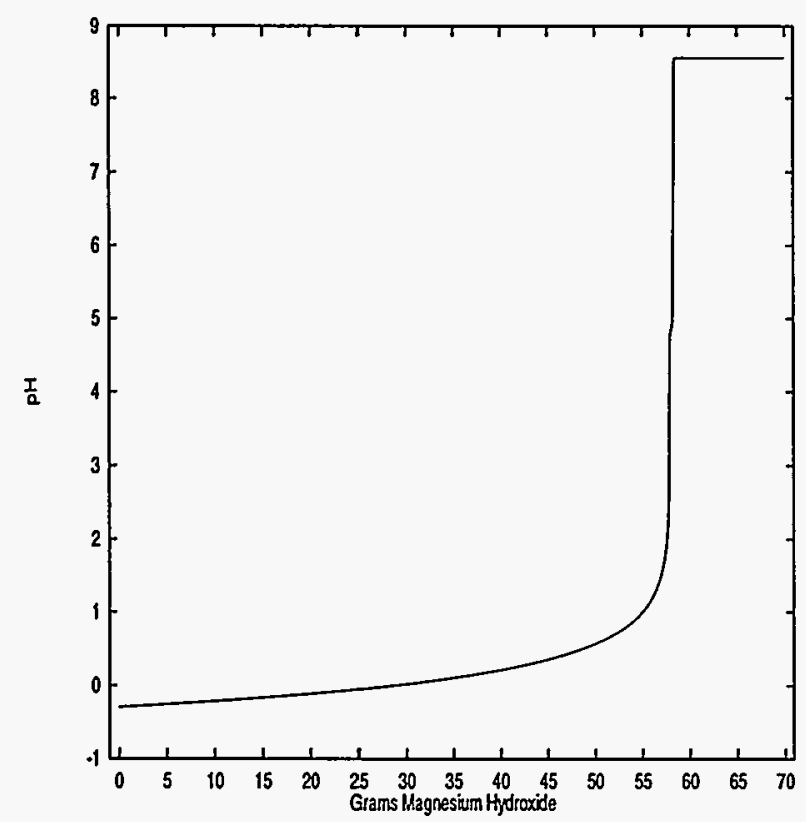

Figure 1: Simulated titration curve

\section{Process Model Assumptions}

The preceding model contains six unknowns, the concentrations of each of the ionic species, with only four equations. Further information can be obtained from the standard potassium hydroxide titration performed on each batch. This titration determines the initial moles of acid and heavy metals, which precipitate, in the charged effluent. Since hydrochloric acid is the only acid present, all the metals are dissolved as chlorides, and the alkali metals do not precipitate, it is reasonable to assume that this quantity is also the difference between the moles of chloride and the moles of alkali in solution. This difference remains constant throughout the reaction because magnesium hydroxide addition cannot precipitate chloride or alkali ions. Therefore the charge balance in Eq. 7 can be expressed as follows in which $\left[\mathrm{C}^{-}\right]$represents the difference between the chloride and alkali concentrations in the effluent determined by titration.

$$
3\left[\mathrm{M}^{+3}\right]+2\left[\mathrm{Mg}^{+2}\right]+\left[\mathrm{H}^{+}\right]=\left[\mathrm{OH}^{-}\right]+\left[\mathcal{C}^{-}\right]
$$

This model assumes that the actinides and other heavy metals present can be represented by a single species with the solubility product of the most soluble metal hydroxide. Normally this is a poor assumption that can lead to significant error in the predicted concentrations. However, with such a large difference in solubility between the heavy metal and magnesium hydroxides and a relatively low concentration of heavy metals in this process, this assumption is justified. Simulation studies with varying solubility products and multiple heavy metal species show almost no change in the predicted end points.
Another simplification in the model is the assumption that plutonium remains as $\mathrm{Pu}^{+3}$ throughout the reaction. A unique property of plutonium is its ability to co-exist in two or more of its four common oxidation states in the same solution [2]. At low pH in hydrochloric acid, the plutonium is mostly $\mathrm{Pu}^{+3}$. At the end point, the precipitated plutonium hydroxide is essentially all $\mathrm{Pu}^{+4}$. The transition from $\mathrm{Pu}^{+3}$ to $\mathrm{Pu}^{+4}$ occurs as the $\mathrm{pH}$ increases through a series of disproportionation and hydrolysis reactions that involve higher oxidation states. Since the concentration of plutonium is relatively low, the error introduced by ignoring this transition is small and does not necessitate additional complexity in the model.

Magnesium can be present in the feed stream from the magnesium oxide crucibles that are used in the electro-refining of plutonium. These crucibles typically are dissolved in hydrochloric acid along with the contents for processing. It is assumed that there are no other sources of magnesium in the effluent in addition to the crucibles.

The loss-in-weight feeder provides an accurate measure of the mass of magnesium hydroxide powder added, but not the concentration in solution. The calculated magnesium concentration is determined as

$$
\left[\mathrm{Mg}^{+2}\right]_{c}=\frac{M}{w_{m} V}+\left[\mathrm{Mg}^{+2}\right]_{i}
$$

in which $M$ is the total mass of magnesium hydroxide powder added, $w_{m}$ is the molecular weight of magnesium hydroxide, $V$ is the volume of the reactor contents, and $\left[\mathrm{Mg}^{+2}\right]_{i}$ is the initial magnesium concentration of the charged effluent due to dissolved crucibles. The charged volume is determined from the differential pressure measurement assuming that the density of the solution remains constant. The initial magnesium concentration is determined from the crucible mass and the total effluent volume.

The solubility expressions in Eqs. 8 through 10 are valid when the activity coefficient of each species is unity and the reactor is at $20^{\circ} \mathrm{C}$. At the normal acid concentration of the effluent, however, the activity coefficients are not unity. Due to the difficulty in estimating activity coefficients in high ionic strength solutions, the error introduced by the use of estimated activity coefficients is on the order of the error introduced by assuming unit coefficients. Therefore, the model will not account for activity or temperature changes. This simplification is the greatest source of model error.

\section{End Point Control Algorithm}

The amount of magnesium hydroxide necessary to reach the end point can be determined by the model after the effluent is charged to the reactor and titrated. However, there are measurement errors associated with the titration, volume charged to the 
reactor, and magnesium concentration. These errors along with the modeling error can lead to a significant error in the calculated amount of magnesium hydroxide required. For this reason, the end point is approached by a series of magnesium hydroxide additions in which the $\mathrm{pH}$ measurement is used to update the model on-line [3]. This technique is similar to the end point controller in [4].

\subsection{Magnesium Hydroxide Addition}

The principle tuning parameter of the control algorithm is the number of magnesium hydroxide additions to perform. As this number increases, the end point controller approaches a feedback $\mathrm{pH}$ controller. A limit on the number of additions is the inability of the magnesium hydroxide feed system to precisely feed and pneumatically transport single gram quantities into the reactor.

The magnesium concentration required to achieve the end point is calculated by solving the nonlinear series of equations in Eqs. 8 through 11.

$$
\begin{aligned}
2\left[\mathrm{Mg}^{+2}\right]_{e p} & =\left[\mathrm{OH}^{-}\right]+\left[\mathrm{C}^{-}\right]-\left[\mathrm{H}^{+}\right]-3\left[\mathrm{M}^{+3}\right] \\
\mathrm{K}_{\mathrm{W}} & =\left[\mathrm{H}^{+}\right]\left[\mathrm{OH}^{-}\right] \\
\mathrm{K}_{\mathrm{MB}_{\mathrm{B}}} & =\left[\mathrm{Mg}^{+2}\right]\left[\mathrm{OH}^{-}\right]^{2} \\
\mathrm{~K}_{\mathrm{M}} & =\left[\mathrm{M}^{+3}\right]\left[\mathrm{OH}^{-}\right]^{3}
\end{aligned}
$$

The total amount of magnesium hydroxide powder necessary is determined by rearranging Eq. 12

$$
M_{t}=w_{m} V\left(\left[\mathrm{Mg}^{+2}\right]_{e p}-\left[\mathrm{Mg}^{+2}\right]_{i}\right)
$$

in which $\left[\mathrm{Mg}^{+2}\right]_{e p}$ is the estimated magnesium concentration at the endpoint from Eq. 13 and $\left[\mathrm{Mg}^{+2}\right]_{i}$ is the initial magnesium concentration of the effluent.

The amount of magnesium hydroxide powder to add on the $i$ th addition is computed based on the model predicted total amount needed to achieve the end point, $M_{t}$, the amount previously added, $M_{i-1}$, and the fraction, $f_{i}$, discussed in the next section.

$$
\begin{aligned}
\Delta M_{i} & =f_{i}\left(M_{t}-M_{i-1}\right) \\
M_{i} & =M_{i-1}+\Delta M_{i}, \quad M_{0}=0
\end{aligned}
$$

The computed addition, $\Delta M_{i}$, is adjusted to respect maximum and minimum constraints. The minimum constraint represents the smallest quantity that can reliably be fed into the reactor.

If the model determines that the end point has been achieved before the last addition, a warning message is reported to the operator and the automatic addition sequence is terminated. The controller also checks the $\mathrm{pH}$ after the last addition to ensure that undershoot of the end point did not occur. If the $\mathrm{pH}$ is too low, an error message is reported and either manual corrective action or a subsequent addition is performed.

\subsection{Process Model Update}

Model updating can be accomplished by computing an estimate of the $\mathrm{pH}$ based on the known amount of magnesium hydroxide added and comparing this estimate to the measured value. The equations used to compute this estimate depend on the measured $\mathrm{pH}$ of the solution. At low $\mathrm{pH}$, the heavy metals are still in solution and Eq. 10 is not valid. Since the heavy metal concentration is low, $\mathrm{pH}<<\mathrm{pM}$ and it is reasonable to neglect the heavy metal ions in the charge balance. The hydrogen ion concentration is then computed from the following equations in which $\left[\mathrm{Mg}^{+2}\right]_{c}$ is determined from Eq. 12.

$$
\begin{aligned}
{\left[\mathrm{H}^{+}\right] } & =\left[\mathrm{OH}^{-}\right]+\left[\mathcal{C}^{-}\right]-2\left[\mathrm{Mg}^{+2}\right]_{c} \\
\mathrm{~K}_{\mathrm{w}} & =\left[\mathrm{H}^{+}\right]\left[\mathrm{OH}^{-}\right]
\end{aligned}
$$

As the end point is approached, the heavy metals begin to precipitate and Eq. 10 is valid. The following series of equations are then used.

$$
\begin{aligned}
{\left[\mathrm{H}^{+}\right] } & =\left[\mathrm{OH}^{-}\right]+\left[\mathrm{C}^{-}\right]-3\left[\mathrm{M}^{+3}\right]-2\left[\mathrm{Mg}^{+2}\right]_{c} \\
\mathrm{~K}_{\mathrm{w}} & =\left[\mathrm{H}^{+}\right]\left[\mathrm{OH}^{-}\right] \\
\mathrm{K}_{\mathrm{M}} & =\left[\mathrm{M}^{+3}\right]\left[\mathrm{OH}^{-}\right]^{3}
\end{aligned}
$$

The most unreliable process measurement is the titration of the charged effluent that determines the initial value of $\left[\mathrm{C}^{-}\right]$. Therefore, it is this value that is adjusted to update the model. A new value of $\left[\mathrm{C}^{-}\right]$ is determined by minimizing the following recursive weighted least squares objective.

$$
\min _{\left[\mathcal{C}^{-}\right]_{i+1}}\left(\left[\mathcal{C}^{-}\right]_{i+1}-\left[\mathcal{C}^{-}\right]_{i}\right)^{2}+w\left(\mathrm{pH}_{i}-\mathrm{pH}_{i}\right)^{2}
$$

In this objective, $\mathrm{pH}_{i}$ is the estimated $\mathrm{pH}$ determined from either Eq. 16 or Eq. 17, $\mathrm{pH}_{i}$ is the measured $\mathrm{pH}$, and $\left[\mathrm{C}^{-}\right]_{i+1}$ is the updated chloride concentration after the $i$ th addition. The weighting factor $w$ is the tuning parameter for the estimator.

\section{Results}

Because of the toxicity and radiation problems associated with actinide solutions, the initial equipment testing and verification of the end point controller was carried out using non-radioactive effluent solutions. This procedure has been a reliable indication of a technique's performance when applied to the actual process in the past [1]. The results presented in this work are from these 'cold' studies.

The effluent solutions in these tests contained iron as the heavy metal component in place of actinides. A low metal loading, $1 \mathrm{~g} / \mathrm{l}$, and a high metal loading, $5 \mathrm{~g} / \mathrm{l}$, were studied in the initial tests. These metal loadings bracket the range that typically is encountered in the process. 


\subsection{Controller Tuning}

Based on the iron effluent solutions, four to six magnesium hydroxide additions are recommended. This range provides a reasonably consistent approach to the end point without requiring the addition of single gram quantities. One of the factors determining the number of additions chosen for a batch is the charged volume of the reactor. Fewer additions are necessary for low volume batches in order to avoid the problems associated with small additions.

The algorithm used to determine the fraction of magnesium hydroxide added at each addition, $f_{i}$ in Eq. 15, was determined heuristically in which $n$ is the total number of additions.

$$
f_{i}=\left\{\begin{aligned}
1-0.05(n-1), & i=1 \\
i / n, & 1<i<n \\
1+\delta, & i=n
\end{aligned}\right.
$$

This algorithm results in a large initial addition when the reaction is far from the end point, smaller intermediate fractional additions that are used to update the model, and then larger fractions near the end point. The tuning parameter $\delta$ is specified to provide an excess of magnesium hydroxide on the last addition. It is discussed in more detail in Section 7.2.

The tuning parameter $w$, which is used in the model update of the estimated chloride concentration in Eq. 18, was normally chosen to be unity due to suspected error in the $\mathrm{pH}$ measurements. The principle source of this error was the temperature variation in the reactor due to the heat generated by the neutralization reaction.

\subsection{Example}

Table 1 presents the results using four additions for a batch with $1 \mathrm{~g} / \mathrm{l}$ metals loading. As shown in the table, the algorithm undershot the end point by about $0.6 \mathrm{~g} / \mathrm{l}$ after the fourth addition. This addition was determined with $\delta=0$. The algorithm was then used to compute a fifth addition with $\delta=0.5$ that essentially reached the end point. In practice, a small amount of magnesium hydroxide would be added manually to complete the batch in this case. The value of $\left[\mathrm{C}^{-}\right]$was determined using $w=1$ with the initial value determined from a standard titration.

The undershoot of the end point presented in this example is typical of the results experienced with the iron solutions. It is for this reason that the tuning parameter $\delta$ was included in the control algorithm. The major cause appears to be the limited solubility of magnesium hydroxide near the end point. The result is incomplete dissolution during the ten to twenty minute sample periods used for the final additions. Modeling error also is a contributing factor as shown by the sensitivity of the computed additions on the model parameter $\left[\mathrm{C}^{-}\right]$near the end point.

\begin{tabular}{|c|c|c|c|c|}
\hline \hline & $\Delta M_{i}$ & {$\left[\mathcal{C}^{-}\right]_{i}$} & $\mathrm{pH}$ & $\mathrm{pH}$ \\
$i$ & $\mathrm{~g} / \mathrm{l}$ & $\mathrm{M}$ & Measured & Predicted \\
\hline 1 & 22.06 & 1.02 & 0.61 & 0.58 \\
2 & 3.72 & 1.01 & 1.87 & 0.90 \\
3 & 0.93 & 0.92 & 2.22 & 2.43 \\
4 & 0.31 & 0.92 & 2.45 & 8.71 \\
\hline 5 & 0.57 & 0.94 & 7.29 & 8.71 \\
\hline \hline
\end{tabular}

Table 1: Example batch run

\section{Conclusions}

An end point control algorithm for the actinide precipitation reactors at Los Alamos National Laboratory has been developed and tested on nonradioactive effluent solutions. The results of these tests show that the controller is able to consistently approach the end point. With end point control, it is expected that manual additions on the order of $1 \mathrm{~g} / \mathrm{l}$ will be required to complete a batch as opposed to the current manual additions that are on the order of 60 $\mathrm{g} / \mathrm{l}$. For this reason, it is anticipated that end point control can provide significant reduction in the excess magnesium hydroxide over the current operation.

An improvement to the control strategy is the installation of a reactor temperature sensor and temperature compensation of the $\mathrm{pH}$ measurement. Increased reliability of the measured $\mathrm{pH}$ would allow a more aggressive model correction based on these measurements. The result would be a more reliable approach to the end point.

\section{References}

[1] M. J. Palmer and K. W. Fife. Magnesium hydroxide as the neutralizing agent for radioactive hydrochloric acid solutions. Technical Report LA-12975-MS, Los Alamos National Laboratory, 1995.

[2] J. M. Cleveland. The Chemistry of Plutonium. American Nuclear Society, LaGrange Park, IL, 2nd edition, 1979.

[3] D. Ruppen, D. Rippin, and D. Bonvin. An online optimization strategy for fast batch and semibatch reaction systems. In Proceedings of the 1991 ADCHEM Symposium, 1991.

[4] J. B. Rawlings, N. F. Jerome, J. W. Hamer, and T. M. Bruemmer. End-point control in semi-batch chemical reactors. In Proceedings of the IFAC Symposium on Dynamics and Control of Chemical Reactors, Distillation Columns, and Batch Processes, pages 323-328, 1989. 